\section{Bifunctional Thiourea Organocatalyst Enables a Halocyclization and Spiroketalization Cascade}

\section{Category}

Organo- and

Biocatalysis

Key words

halocyclization

spirocyclization

hydrogen-bond donor catalysis

dynamic kinetic resolution

cascade reaction<smiles></smiles><smiles>[X]N1C(=O)CCC1=O</smiles>
or<smiles>[X]C1C(=O)N(Cl)C(c2ccccc2)(c2ccccc2)C1=O</smiles>
$\mathrm{X}=\mathrm{Br}$ (NBS) $\mathrm{X}=\mathrm{I}$ (NIS)

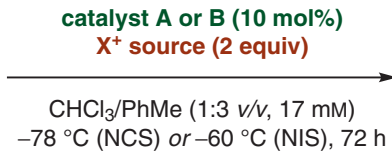

$\mathrm{PhMe}(17 \mathrm{mM})$ $-60{ }^{\circ} \mathrm{C}(\mathrm{DCDPH}), 72 \mathrm{~h}$

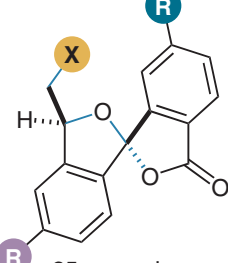

25 examples yield from 57 to $93 \%$ dr from 23:1 to $>99: 1$ er from $95: 5$ to $99.5: 0.5$
R $=\mathrm{H}, \mathrm{Me}, \mathrm{F}, \mathrm{Cl}, \mathrm{CF}_{3}$

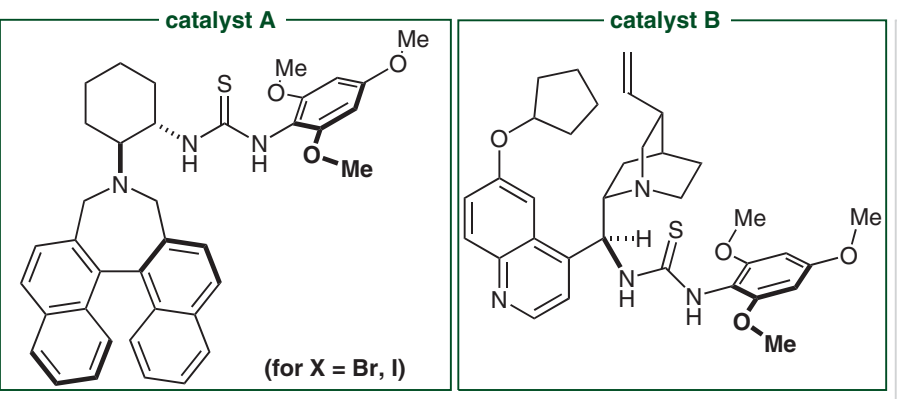

Enantio- and diastereoselective chloro-bis-spiroketalization
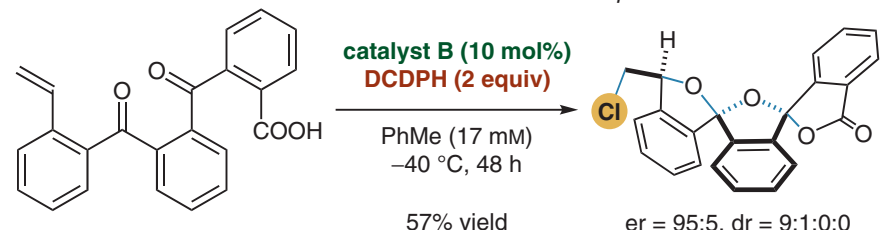

er $=95: 5, d r=9: 1: 0: 0$

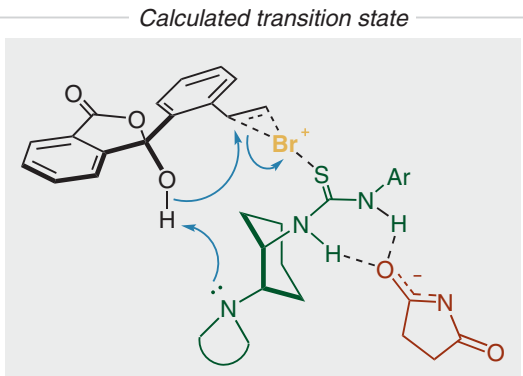

Synthesis of natural product analogue

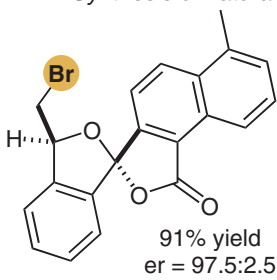

$\mathrm{dr}>99: 1$
Significance: Tse, Yeung, and co-workers report an enantio- and diastereoselective domino halocyclization and spiroketalization of styryl keto acids. In the presence of an electron-rich bifunctional thiourea organocatalyst and the appropriate electrophilic halogen source, the corresponding spirocyclic products are obtained in good to excellent yields and with excellent diastereo- and enantioselectivities. The method can be extended toward an enantio- and diastereoselective chloro-dispiroketalization. Additionally, the authors demonstrate its applicability in the synthesis of structural analogues of danshenspiroketallactone, a naturally occurring monobenzannulated 5,5-spiroketal.
Comment: The reported method expands the toolbox of catalytic asymmetric electrophilic halocyclizations, which previously focused on polyenes as substrates to provide fused-ring systems (R. C. Samanta, H. Yamamoto J. Am. Chem. Soc. 2017, 139, 1460). Mechanistic studies suggest that the transformation involves a dynamic kinetic resolution of the hemiketal form of the starting material, followed by activation of the halogen and asymmetric halocyclization. Intriguingly, an electron-rich thiourea catalyst is required for high enantioselectivities as opposed to its commonly used electrondeficient congeners. The authors propose that electron-donating substituents lead to an enhanced interaction between the halogen source and the sulfur atom of the thiourea. 